Western University

Scholarship@Western

Aboriginal Policy Research Consortium International (APRCi)

2005

\title{
The Experience of Urban Aboriginals with Health Care Services in Canada
}

Ron Levin

Margot Herbert

Follow this and additional works at: https://ir.lib.uwo.ca/aprci

Part of the Social Work Commons

Citation of this paper:

Levin, Ron and Herbert, Margot, "The Experience of Urban Aboriginals with Health Care Services in Canada" (2005). Aboriginal Policy Research Consortium International (APRCi). 263.

https://ir.lib.uwo.ca/aprci/263 
This article was downloaded by: [University of Western Ontario]

On: 10 December 2012, At: 08:04

Publisher: Routledge

Informa Ltd Registered in England and Wales Registered Number: 1072954

Registered office: Mortimer House, 37-41 Mortimer Street, London W1T 3J H, UK

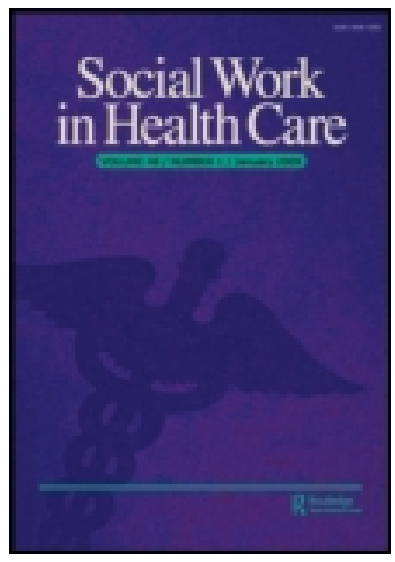

\section{Social Work in Health Care}

Publication details, including instructions for authors and subscription information:

http:// www. tandfonline.com/loi/ wshc20

\section{The Experience of Urban Aboriginals with Health Care Services in Canada}

Ron Levin MSW, RSW ${ }^{a} \&$ Margot Herbert MSW, RSW ${ }^{\text {a }}$

a University of Calgary, Faculty of Social Work, Edmonton Division, \#444, 11044-82 Avenue,

Edmonton, AB, T6G 0T2, Canada

Version of record first published: 08 Oct 2008.

To cite this article: Ron Levin MSW, RSW \& Margot Herbert MSW, RSW (2005): The Experience of Urban Aboriginals with Health Care Services in Canada, Social Work in Health Care, 39:1-2, 165-179

To link to this article: http:// dx.doi.org/10.1300//010v39n01_11

\section{PLEASE SCROLL DOWN FOR ARTICLE}

Full terms and conditions of use: http://www.tandfonline.com/page/termsand-conditions

This article may be used for research, teaching, and private study purposes. Any substantial or systematic reproduction, redistribution, reselling, loan, sub-licensing, systematic supply, or distribution in any form to anyone is expressly forbidden.

The publisher does not give any warranty express or implied or make any representation that the contents will be complete or accurate or up to date. The accuracy of any instructions, formulae, and drug doses should be independently verified with primary sources. The publisher shall not be liable for any loss, actions, claims, proceedings, demand, or costs or damages 
whatsoever or howsoever caused arising directly or indirectly in connection with or arising out of the use of this material. 


\title{
CITIZENSHIP AND PARTICIPATION OF USERS
}

\section{The Experience of Urban Aboriginals with Health Care Services in Canada: Implications for Social Work Practice}

\author{
Ron Levin, MSW, RSW \\ Margot Herbert, MSW, RSW
}

\begin{abstract}
SUMMARY. This exploratory study investigates the experience of Canadian Urban Aboriginal persons as consumers of health care services. Results highlight significant gaps in the training, skills, and knowledge of health care providers to optimally serve their Aboriginal patients. Also, several programs which are potentially most problematic for Aboriginal patients are identified. The discussion outlines important roles for hospital social workers in improving the care provided to urban Aboriginal patients.
\end{abstract}

Ron Levin is Associate Professor, University of Calgary, Faculty of Social Work, Edmonton Division, \#444, 11044-82 Avenue, Edmonton, AB T6G 0T2, Canada (E-mail: rlevin@ualberta.ca). Margot Herbert is Associate Professor Emerita, University of Calgary, Faculty of Social Work, Edmonton Division, \#444, 11044-82 Avenue, Edmonton, AB T6G 0T2, Canada (E-mail: fherbert@ualberta.ca).

[Haworth co-indexing entry note]: "The Experience of Urban Aboriginals with Health Care Services in Canada: Implications for Social Work Practice." Levin, Ron, and Margot Herbert. Co-published simultaneously in Social Work in Health Care (The Haworth Social Work Practice Press, an imprint of The Haworth Press, Inc.) Vol. 39, No. 1/2, 2004, pp. 165-179; and: Social Work Visions from Around the Globe: Citizens, Methods, and Approaches (ed: Anna Metteri et al.) The Haworth Social Work Practice Press, an imprint of The Haworth Press, Inc., 2004, pp. 165-179. Single or multiple copies of this article are available for a fee from The Haworth Document Delivery Service [1-800-HAWORTH, 9:00 a.m. - 5:00 p.m. (EST). E-mail address: docdelivery@haworthpress.com].

http://www.haworthpress.com/web/SWHC

(C) 2004 by The Haworth Press, Inc. All rights reserved.

Digital Object Identifier: 10.1300/J010v39n01_11 
[Article copies available for a fee from The Haworth Document Delivery Service: 1-800-HAWORTH. E-mail address: <docdelivery@haworthress.com> Website: <http://www. HaworthPress.com> (C) 2004 by The Haworth Press, Inc. All rights reserved.]

KEYWORDS. Urban Aboriginal consumers, health care services

\section{INTRODUCTION}

\section{The Canadian Health Care System}

A federal, ten provincial and two territorial governments govern Canadians. According to the provisions of the Canadian constitution (1867), the provinces have jurisdiction for the organization and delivery of health care along with other public services including education and social welfare. There are, however, several populations for whom the federal government retains primary responsibility for delivery of health services. These include members of the armed forces, the R.C.M.P., offshore federal employees, prisoners in federal facilities, and Aboriginal persons who are registered under the Indian Act of Canada. In order to ensure equality of health services to all Canadians, the federal government shares the cost of health care with the provinces. In 1996, the Canada Health and Social Transfer Act, which is the most recent legislation in this area, arranged for the transfer of a "block of funds," consisting of cash payments and "tax points" from the federal government to the provinces. This was to be applied towards hospital and medical insurance, post secondary education and welfare programs. The allocation of resources between these programs was left to the discretion of the provincial governments. However, the Canada Health Act (1984) stipulates the conditions with which provinces must comply to receive cash transfers each year. These conditions include: (a) public administration-the provincial health care insurance plan must be "administered and operated on a non profit basis by a public authority appointed or designated by the government of the province." This provision does not say who actually delivers the health care services; (b) comprehensiveness-the provincial health care insurance plan must " insure all insured health services provided by hospitals, medical practitioners or dentists, and where the law of the province so permits, similar or additional services rendered by other health care practitioners"; (c) universality-to satisfy this criterion the provincial insurance plan must "entitle one hundred percent of the insured 
persons of the province to the insured health services provided for by the plan on uniform terms and conditions"; (d) portability-this criterion requires that Canadians be covered when traveling within and outside of Canada, at the rate of their home province. Also it stipulates that the provincial plan "must not impose any minimum period of residence in the province, or waiting period in excess of three months before residents of the province are eligible or entitled to insured health services"; and (e) accessibility-this provision requires that the provincial plan "must provide for insured services on uniform terms and conditions and on the basis that does not impede or preclude, either directly or indirectly whether by charges made to insured persons or otherwise, reasonable access to those services by insured persons." Also the province must "provide for reasonable compensation for all insured health services rendered by medical practitioners or dentists" and pay hospitals for the "cost of insured health services." The CHA also sets out penalties if a province allows extra billing by health care providers or sets user fees.

\section{Context}

There are approximately 800,000 people in Canada who identify themselves as Aboriginal. ${ }^{1}$ About 20 percent live in the seven largest cities in Canada, and another 25 percent live in smaller urban centers (Statistics Canada 1998). Over time, Aboriginal people in Canada have been subjected to systematic colonization and domination. Federal policy historically emphasized assimilation through such means as forcing Aboriginal children to attend residential schools away from their reserves and families, and adoption of Aboriginal children into non-Aboriginal families. It cannot be denied that the experience of oppression continues to affect Aboriginal individuals, families, and communities today. Our limited appreciation of the history, traditions, and values of Aboriginal people, and the impact of these experiences, represent a challenge for those who work with this population. A further challenge is that within the larger population of Aboriginal people there are many different language groups, tribal groups, and geographic settings. As well, it is necessary to distinguish between traditionalists and assimilated Aboriginal people, and those who may have found a way to bridge both the traditional world with modern reality (Morrissette et al., 1993). In spite of these differences, there tends to be a common "world view" among Aboriginal people, characterized by such fundamental beliefs as a connection to the earth which contributes to healing; a holistic view of the universe; a spiritual dimension infusing all aspects of a person's life; a belief that all creatures are linked and mutually interdependent for survival; and that supernatural 
phenomena constantly affect their lives. This perspective emphasizes harmony, natural laws, and rhythms of nature and sets the context for a group of values that can include, self-determination, a focus on the present, and adherence to traditional healing practices. These dominant characteristics continue to influence the lives of many Aboriginal people.

There is evidence that Aboriginal people are more likely to suffer from hypertension, heart disease, diabetes and other chronic illnesses than their non-Aboriginal counterparts (Shah, Hux, \& Zinman 2000), and are therefore disproportionately represented on patient rolls of hospitals and outpatient health services. Although there is research that speaks to the broader socio-economic-cultural determinants of this situation, the actual health care experiences of Aboriginal people in Canada and elsewhere have not been well described (Cheung \& Snowdon 1999; Strickland 1999). Since most health care providers are not Aboriginal, there is almost certainly some degree of cultural dissonance, which affects the ways that services are used and experienced by Aboriginal people (Mokuau \& Fong 1994; Sanchez \& Plawecki 1996; Weaver 1999) and may create barriers for those who seek help with health-related problems.

\section{LITERATURE REVIEW}

Mokuau and Fong (1994) suggest that the responsiveness of health services may be measured according to three criteria: availability, accessibility, and acceptability. It is objectively clear that when services are not readily available or accessible, there is concomitant low utilization. As with other human services, barriers associated with availability and accessibility generally correlate with low socio-economic status, which unfortunately is a reality for a huge majority of the Aboriginal population. Less obvious are barriers to utilization that result from health services offered in a way that is culturally unacceptable. When services are not compatible or congruent with cultural values and traditions, they are much less likely to be accessed, even by those who urgently need those services (Mokuau \& Fong 1994; Weaver 1999).

Willms, Lange, Bayfield, Beardy, Lindsay, Cole, and Johnson (1992) reported that Aboriginal women, in particular, lacked trust in the health care system. Reasons cited include inexperience of doctors and nurses, lack of communication with patients, cultural insensitivity, and lack of knowledge or understanding of native healing practices. In general, health care providers were perceived to be philosophically and physically 
distant from their patients. Although this study was largely based on data from small communities, when moved to hospitals in larger centers these same patients reported feeling neglected and denigrated. General distrust of the system was compounded by difficulties in communication and lack of companionship. Gagnon (1989) also described how native patients who were referred to specialists and tertiary hospitals in urban centers were removed from their usual sources of support and understanding and often found themselves with little cultural, linguistic, and organizational understanding of the hospital.

The existence of serious communication problems between native patients and non-native health care providers was also documented in an earlier study of health facilities in a western Canadian city (Waldram \& Layman 1989). Interestingly, a subsequent study (Waldram 1990) suggested that in some urban centers, the access issue may be more a function of socio economic status than that of being native. This study also suggested that Aboriginals who were most closely affiliated with their Aboriginal roots were more likely to access available health services. This may explain some of the problems of the urban Aboriginal population, many of whom are less grounded in cultural traditions than their rural counterparts.

Shah and Farkus (1985) described the general poor health of Aboriginal people in Canadian cities as a major challenge to the health care system. Their research cited difficulties in communication and unavailability of culturally sensitive health care services as major barriers to good health care. Shestowsky (1995) identified structural and attitudinal barriers as two major shortfalls in meeting the needs of Aboriginal people living in cities. In addition to a lack of information and programs, results pointed to problems in the areas of communication, provision of cultural services, and stereotyping on the part of providers within the health system. The problems faced by urban Aboriginals seeking health care services were also cited in a report sponsored by Alberta Health (Strengthening the Circle 1990). For elders, in particular, communication problems were prominent when seeking medical attention in hospitals or health centers. Other barriers had to do with lack of familiarity with hospital and medical practices; failure of health care staff to explain things; fear of doctors and other white people in authority; unfamiliar food; a feeling that no one was listening to them; and insensitive treatment.

A review of Aboriginal populations in other countries reveals commonalities in health care experiences with their Canadian counterparts. Both Australian Aborigines and Native Americans are also susceptible to the forms of chronic and stress related illnesses observed in Canadian 
Aboriginal people (Lowe \& Kerridge 1995). The actual health experiences of Australian and U.S. Aboriginals have not been well documented. What is described, however, are similar barriers to health care services as experienced by Canadian Aboriginals. Yuki (1986) identified problems encountered by the Native American community of Boston, Massachusetts in their contacts with a major hospital. These issues led her and a colleague to spearhead the development of a specialized clinic within the hospital to fill the gap in meeting the health care needs of the Aboriginal population.

Researchers from Australia and North America have called for culturally competent practice when dealing with the health and human service needs of indigenous people (Jackson \& Ward 1999; Paterson 1997; Weaver 1998). Several efforts towards meeting the needs of urban Aboriginals were described. For example, in the U.S. the federal division of Indian Health Services employs specially trained Native community health representatives to act as liaisons between Native American communities and the health care system (Dubray \& Sanders 1999). A very recent report of a community consultation on the state of urban Aboriginals in Edmonton, Canada found that most Aboriginals who move from rural to urban centers seem to do so for economic reasons. However, the rate of poverty and unemployment they experience seems to indicate that hopes for a better life in the city rarely materialize.

Significant social problems continue to plague a substantial number of urban Aboriginal people, particularly women and youth. High rates of single parent families, difficulty entering the labour market, inadequate housing and inadequate health care remain problems for many Aboriginal people. (The Edmonton Urban Aboriginal Initiative, 1999, p. 70)

The Edmonton study pointed out that although approximately half of the Aboriginal people in Canada live in urban areas, relatively little research has been done relating to the health needs of this population.

\section{METHOD}

Seven key respondents were identified based on recommendations provided by informants with professional and personal knowledge of Aboriginal issues. The criteria for selection of key respondents were that each: (a) held a position which required frequent and broad interac- 
tion with urban Aboriginals, (b) possessed a comprehensive understanding of Aboriginal issues as well as the health care system, and (c) was able to clearly articulate his/her views. Six respondents were females and one male. Five were Aboriginal. Respondents included health professionals, administrators of Aboriginal health programs and directors of large inner-city health and social service agencies. We telephoned all key respondents to explain the project and to invite their participation. All agreed to allow the interviews to be tape-recorded. We then faxed the questionnaire together with a covering letter to each respondent several days before the interview. These letters confirmed the purpose of the project, the method, and time and date of appointment. Interviews were between 1-1/2 to two hours in length.

The questionnaire consisted of six open-ended questions. Three questions focused on the knowledge, skills, and attitudes of health professionals, two inquired about hospital programs and health services, and the final question asked the respondent to suggest changes which would make the health system more user friendly for urban Aboriginals. We utilized a grounded theory approach in which we incorporated input from one interview into the next, in order to obtain a final picture, which was as comprehensive as possible. After all interviews were completed, the audiotapes were reviewed, and responses were summarized and grouped into themes.

\section{RESULTS}

\section{Knowledge}

All respondents acknowledged that health care professionals possess the requisite technical knowledge to treat patients. However, they all indicated that there are profound difficulties in delivering treatment effectively to urban Aboriginals. According to one respondent, "professionals have scientific knowledge but not Aboriginal wisdom. Professionals are focused on scientific measurement but they can only measure twenty-five percent of the picture. They can't measure love, spirit, or emotion." Respondents asserted that the Aboriginal belief system emphasizes wholeness and the interconnection between mind, body, emotion, and spirit while western medicine reduces people to a collection of organs or diseases. Aboriginal spirituality is manifested in rituals such as the pipe ceremony, praying, smudging, circles, and sweats that are incongruent with highly secular western medicine. Three of the respondents indicated that 
many health professionals are respectful and motivated to learn but lacked training and sufficient insight.

There was significant agreement concerning the role of traditional culture in the lives of urban Aboriginals, particularly those who spend most of their time in the city. Some respondents insisted that most urban Aboriginal persons visit their home communities often and thus continue to be tuned in to their culture. Even those who visit infrequently are "seeking cultural wisdom and yearn to come to the well." However, several respondents pointed out that it is important not to assume that all Aboriginal people are the same. There are often differences in adherence to spiritual beliefs and practices, religious affiliation, kinship and interpersonal relationships, and lifestyle. These differences are based on various factors including personal life experience, socioeconomic status, education, and experience with non-Aboriginals.

Another gap in the knowledge of health care professionals identified by four respondents related to an understanding of the culture of poverty that is the lived reality of many urban Aboriginals. Health care treatment is often premised on having a place to live, food, financial resources, and expectations by health professionals of patient compliance are based on those assumptions. Another lived experience for many urban Aboriginals is growing up in institutional care. Several respondents also indicated that lack of knowledge on the part of health care professionals concerning traditional Aboriginal lifestyle is problematic, particularly when treating elderly urban Aboriginals and persons who spend a lot of time on their home reserves. Differences in diet, pace of life, air and water quality can all contribute to a sense of alienation.

\section{Skills}

All respondents agreed that health care professionals have the requisite technical competence but most do not possess the particular skills necessary to care for urban Aboriginal patients effectively. Primary among the skill deficits identified was communication and rapport building. Most often stressed by the respondents was the importance of listening. Aboriginals, particularly the elderly and inner city residents, are customarily not assertive in communication style so the listener must be patient and attentive to the message. This rarely happens in the hectic and fast paced health care environment. One respondent related the example of a diabetic man who refused to seek treatment because he felt that the health professionals had not listened to him. Another indicated that urban Aboriginals who were 
raised in Aboriginal communities often think in their first language even if not currently fluent in that language. Aboriginal languages often contain nuances not easily translatable into English. This posed difficulties when an Aboriginal patient had to absorb complex information and respond to health professionals in English, particularly when that Aboriginal person was in distress or affected by medications or alcohol. As a result, many Aboriginals in such situations felt humiliated and ridiculed. In a similar vein, another respondent asserted that health care providers usually do not have the skills to appropriately frame their questions, deal with spiritual issues, or approach an Aboriginal elder.

\section{Attitudes and Values}

All respondents asserted that health professionals lack the requisite attitudes and values to effectively serve Aboriginal consumers. The predominant scientific view has a different conceptualization of illness, a different orientation to time, and does not acknowledge the "sacred" (spirituality). Aboriginal attitudes and values as modeled by elders are more balanced in mind, body, emotions, and spirit. Also, the expert stance taken by most health professionals in dealing with patients contradicts the expectations of equality and mutual respect held by Aboriginal consumers.

Six respondents indicated that urban Aboriginals often experience discrimination and racism from health care providers. This stems, in part, from systemic discrimination imposed on Aboriginals and is compounded by policies and practices of health care institutions and providers. Ignorance of Aboriginal culture and traditions are also key factors. All respondents indicated that cross-cultural training can be crucial in changing this situation. However, several questioned whether such training could change basic attitudes. One respondent indicated that cross-cultural training (particularly Aboriginal specific content) is often absent from the education of health care providers and when present, offers only generalities and stereotypes. Such training rarely addresses urban Aboriginal realities defined by racism and poverty, nor the complex interplay between Aboriginal culture and the culture of poverty.

\section{Problematic Services/Programs}

Six respondents cited obstetrics/gynecology as a program that is most problematic for urban Aboriginals. One indicated that younger women often 
are uncomfortable with male physicians and when they are pregnant often do not consult a physician until the day they deliver. These women often worry that the doctor will be judgmental about their age and lifestyle. All agreed that another concern is the perceived possibility of intervention by child welfare authorities. While this concern is particularly strong for under-age women, it also felt by others who have a history of child welfare involvement and/or are single, without income. Another stated that grandparents might be afraid of losing grandchildren because the child welfare system considers them too old to provide appropriate care.

Five respondents indicated that emergency departments also pose problems. Aboriginal persons who tend not to see a physician until they are in severe pain use these departments more often. These respondents asserted that Aboriginals are often the victims of discrimination, citing numerous anecdotal accounts of being passed over in favour of less ill non-Aboriginals. Because many Aboriginals tend not to be assertive, they will leave before they are treated, even if acutely ill. These people will then often use non-prescription remedies or will borrow prescribed medications from friends. One respondent also cited problems with psychiatric services. Since there is little access to services in rural settings, Aboriginals use the urban mental health system, which they often experience as impersonal and discriminatory.

\section{Health Care Settings}

None of the respondents identified the health care setting (whether physician's office, community clinic, or hospital) as particularly responsive to the experience of Aboriginal consumers. Several expressed the view that all settings create fear and lack of trust on the part of Aboriginals who often experience discrimination and stigmatizing behavior. This is particularly true if the person is "not attractive" (defined by the respondent as possessing very pronounced Aboriginal features), is not well dressed, or behaves differently from non-Aboriginals. This situation is exacerbated by the fact that the entire health care system is underfunded and therefore professionals are too stretched to provide individualized care and attention. This is compounded by the fact that there are very few Aboriginal health professionals. Another aggravating factor is that a significant number of urban Aboriginal people lack supportive friends and family who can assist with childcare or transportation. Another issue mentioned by respondents had to do with the problem of keeping appointments scheduled months in advance since inner city Aboriginals tend to change residences frequently. 


\section{Recommended Changes}

All respondents cited the importance of increasing the number of Aboriginal health care professionals and decision-makers. However, several identified barriers to this objective including lack of emphasis on science for Aboriginal students, lack of designated spots for Aboriginals in training programs, and lack of sensitivity to Aboriginal culture on the part of advanced education institutions.

Several respondents expressed the need for urban-based Aboriginal health centers with appropriate child care facilities and transportation. Others identified the need for staffing medi-centers and inner city agencies with nurse practitioners to reduce the use of hospital emergency departments. In addition, several respondents suggested outreach centers within emergency departments and the need for family residences to bolster kinship ties between urban Aboriginals and non-urban family members. The importance of expanded recognition and utilization of Aboriginal medicine as an adjunct to western treatment was also emphasized. Several respondents did cite some recent positive developments in specific hospitals. These included the establishment of native liaison positions, "gathering rooms" for patients and families, and acceptance of traditional ceremonies and foods.

\section{DISCUSSION}

Given the relatively small number of respondents in this study, results must be seen as preliminary and treated with caution. Nevertheless, it is clear that the experience of many Aboriginal people with the urban health care system is affected by various degrees of cultural insensitivity. The remedy, however, is more complex than simply exposing health care providers to courses on cultural sensitivity.

A basic problem is the tendency for well-educated health care providers to bring "expert" solutions to problems. This sort of problem solving, while sometimes necessary and helpful, needs to be tempered with sensitivity to a very different perception of knowledge than the one that comes from western education. In addition to requiring knowledge about "Aboriginal" behavior, those who provide service to this population need to develop communication skills which result in building rapport, and perhaps most importantly, understanding the perspective of 
those who see the world quite differently from most non-Aboriginal people. Clearly Aboriginal people experience overt racism, as well as subtle slights that are interpreted as racially motivated. Unfortunately, many health care providers have encountered Aboriginal people only when they are in the most difficult situations and are most vulnerable. As a result, negative stereotypes have become firm attitudes. Others, who have actually worked in Aboriginal communities, may have had the opportunity to know many healthy and happy Aboriginal people, so will bring a somewhat different perspective.

Most persons who live in chronic poverty, Aboriginals and nonAboriginals, lack sufficient access to the health care system. Many access problems are clearly the result of a system that is generally under resourced. The results of this study indicate, however, that being Aboriginal may create additional problems. There is a complex interplay between the state of poverty and being Aboriginal that is not immediately understood by many non-Aboriginal helpers. Health care providers in a variety of settings are familiar with situations such as the Aboriginal woman who is trying to provide food, clothing, and shelter for her children on an extremely limited income, and confesses that the reason she has not been able to manage is that several family members are staying with her, eating scarce food, and generally disrupting her day-to-day life. Most health care providers would respond to that situation by encouraging this woman (in the name of client empowerment) to get rid of these unwelcome visitors. Often not understood are the cultural norms around this sort of "visiting" which make it impossible for an Aboriginal person to refuse to share with a friend or family member, and asking someone to leave her house would be unacceptable. The cultural norm of visiting is also often evidenced by the number of people who fill the hospital room of a sick friend or relative, sometimes to the annoyance of staff.

Longer than usual waiting time in emergency departments, failure of staff to communicate needed information, and disrespectful attitudes of some health care personnel are clearly experienced as racial bias. Groups that bring particular problems are young Aboriginal women, mothers of young children, and those Aboriginal women for whom seeking medical care from a male doctor is exceedingly difficult and traumatic due to the terrible legacy of authoritarianism and abuse that is so prominent in Aboriginal history. 


\section{RECOMMENDATIONS}

The findings of this exploratory study are particularly relevant for social workers who have a professional obligation to ensure that consumers receive health services in a manner that is respectful and appropriate. In implementing this responsibility, social workers can bolster and enhance their contributions to the health care team as well as their employing organization. Hospital social workers can assume important and useful roles where Aboriginal populations are major users of health facilities. Specific interventions for social workers in health care to consider include the following:

- There are structural impediments for many Aboriginal patients having to do with lack of congruence between levels of government and subsequent confusion among health care providers regarding reimbursement for services. Lack of childcare in health facilities and long delays in accessing specialist care create additional barriers. Hospital social workers should become knowledgeable about these issues in order to fulfill their responsibilities as informed advocates for their Aboriginal clients.

- Social workers who work with Aboriginal clients must understand their worldview, and be sensitive to nuances related to culture, education, and ways of communicating, as well as the possibility that the social workers' own life experiences will affect the way they view this population. To achieve this, social work directors should ensure that their staff has appropriate training from knowledgeable and expert trainers.

- Social work staff and directors should interpret the special needs of Aboriginal patients to other health care providers, and facilitate training in cultural sensitivity for all members of the health care team.

- Directors should encourage and support hiring Aboriginal social workers and native liaison workers, and include the liaison workers as part of the social work department. This must be done with the awareness that the hospital bureaucracy may be a painful reminder for Aboriginal staff of the oppression that they have already experienced from hierarchically structured mainstream organizations.

- Social workers in Obstetrics and Gynecology should be attuned to the special concerns of young Aboriginal mothers, and liaise with local child protection agency and public health units to ensure that 
these women receive support and are not alienated from the systems that can provide needed assistance. Understanding the reluctance of some Aboriginal women to be seen by a male doctor is also crucial.

- Social workers in emergency departments usually encounter the largest number of Aboriginal patients, and have a special responsibility to understand cultural norms, including the culture of poverty, and interpret those norms to other staff.

\section{CONCLUSION}

At a time when hospital social workers are attempting to create new roles and to acquire skills that will reinforce their usefulness in the hospital, there would be enormous "added value" if social workers could lead the way in bridging this very real gap in service for Aboriginal consumers. There is also a message here for those who teach or provide field supervision for social work students, regarding the importance of genuine and skilled cross-cultural practice. Clearly more research is needed in order to better describe and understand this complex issue, so the health care system becomes more available, accessible, and acceptable to urban Aboriginal people.

\section{NOTE}

1. First Nations, Metis and Inuit.

\section{REFERENCES}

Alberta Health Care (1990). Strengthening the Circle.

Cheung, F. K. \& Snowden, L. R. (1990). Community mental health and ethnicity minority populations. Community Mental Health Journal, 26 (3), 277-291.

Dubray, W. \& Sanders, A. (1999). Interactions between American Indian ethnicity and health care. Journal of Health and Social Policy, 10 (4), 67-84.

Edmonton Urban Aboriginal Initiative (1999).

Gangon, Y. (1989), Physician's attitudes toward collaboration with traditional healers. Native Studies Review, 5 (1), 175-185.

Government of Canada. Canada Health Act. (R.S. 1985 c. C-6).

Herbert, M. \& Levin, R. (1995). The advocacy role in hospital social work. Social Work in Health Care, 22 (3), 71-83. 
Jackson, L. R. \& Ward, J. E. (1999). Aboriginal health: Why is reconciliation necessary? Medical Journal of Australia, 170 (9), 437-40.

Lowe, M. \& Kerridge, I. H. (1995). 'These sorts of people don't do very well': Race and allocation of health care resources. Journal of Medical Ethics, 21 (6), 356-60.

Mokaua, N. \& Fong, R. (1994). Assessing the responsiveness of health services to ethnic minorities of colour. Social Work in Health Care, 20 (2), 23-33.

Morrissette, V., McKenzie, B., \& Morrisette, L. (1993). Towards an Aboriginal model of social work practice. Canadian Social Work Review, 10 (1), 91-108.

Paterson, J. M. (1997). Meeting the needs of Native American families and their children with chronic health conditions. Families, Systems and Health, 15 (3), 237-41.

Sanchez, T. R. \& Plawecki, J. A. (1996). The delivery of culturally sensitive health care to native Americans. Journal of Holistic Nursing, 14 (4), 295-307.

Shah, C. \& Farkas, C. (1985). The health of Indians in Canadian cities: A challenge to the health care system. Canadian Medical Association Journal, 133, 859-863.

Shah, B. R., Hux, J. E., \& Zinman. (2000), Increasing rates of ischemic heart disease in the native population of Ontario, Canada. Archives of Internal Medicine, 2000, 160, 1862-66.

Shestowsky, B. (1995). Health-related concerns of Canadian Aboriginal people residing in urban areas. International Nursing Review, 42 (1), 23-6.

Statistics Canada. 1996 Census: Aboriginal data. Ottawa, Canada.

Strickland, R. N. (1999). The importance of qualitative research in addressing cultural relevance: Experience from research with Pacific and Northwest Indian women. Health Care for Women International, 20 (5), 517-25.

Waldram, J. \& Layman, H. (1989). Health care in Saskatoon's inner city: A comparative study of native and non-native utilization patterns. Institute of Urban Studies, Winnipeg, Manitoba.

Waldram, J. (1990). Physician utilization and urban native people in Saskatoon, Canada. Social Science Medicine, 30 (5), 579-589.

Weaver, H. N. (1998). Indigenous people in a multicultural society: Unique issues for human services. Social Work, 43 (3), 203-11.

Weaver, H. (1999). Indigenous people and the social work profession: Defining culturally competent services. Social Work, 44 (3), 217-225.

Willms, D., Lange, P., Bayfield, D., Beardy, M., Lindsay, E. A., Cole, D., \& Johnson, N. (1992). A lament by women for the people, the land [Nishnawbi-Aski Nation]: An experience of loss. Canadian Journal of Public Health, 83 (5), 331-334.

Yukl, T. (1986). Cultural responsiveness and social work practice: An Indian clinic's success. Health and Social Work, 11 (3), 223-9. 